\title{
EL POSITIVISMO LÓGICO *
}

Con el título anterior el profesor Alfred Jules Ayer, de la Universidad de Londres, publicó, en los últimos meses del año próximo pasado, una selección de diecisiete artículos, con el objeto de presentar - dentro de los límites que permite un solo libro- las tesis más características del positivismo lógico.

La tarea de establecer una selección dentro de una área específica del saber, confronta problemas a los que en este caso se aunaban dos dificultades: la primera consiste en hacer la selección, frente a una copiosísima literatura que se inicia desde la segunda década de nuestro siglo y que ininterrumpidamente se continúa hasta nuestros días y la segunda, en precisar ante las denotaciones propuestas para el término "positivismo lógico" cuál debe ser considerada como propia.

No era tarea de la antología el enfrentarse a la investigación y resolución de este segundo problema y su gravedad es menor si consideramos que en los países de habla inglesa la producción filosófica sobre el tema hace que sea ya de suyo conocida la denotación amplia, aquella que tiende a identificarla con lo que Pap llama "filosofía analítica", ${ }^{1}$ con aquella "atmósfera filosófica típica de nuestro tiempo" a que alude v. Wright, ${ }^{2}$ con la situación que confronta Ayer cuando, en la Introducción de la obra que comento, afirma que "Desde aquel tiempo, su referencia [del término 'positivismo lógico'] se ha extendido hasta cubrir otras formas de la filosofía analítica. De manera que discípulos de Russell, G. E. Moore o L. Wittgenstein, de Cambridge o miembros del movimiento contemporáneo de Oxford del análisis lingüístico, pueden hallarse descritos también como positivistas lógicos". 3 Copleston, sobre estos temas, alude a "... lo que podríamos llamar 'mentalidad positivista', que desde luego está mucho más difundida que la filosofía positivista"... 4

Es igualmente conocida la denotación estricta, es decir, aquella que comprende a quienes agrupados en torno a Die Wissenschaftliche Weltauffassung; der Wiener Kreis (1929) constituyeron este "Wiener Kreis", el Círculo de Viena, mantuvieron durante varios años la revista Erkenntnis -más tarde The Journal of Unified Science-y que hostilizados por fuerzas políticas bárbaras hechas gobierno, tuvieron que emigrar a latitudes distantes a proseguir su labor. En este sentido estricto es considerado el positivismo lógico por Ph. Frank, ${ }^{5}$ R. v. Mises, ${ }^{6}$ H. Feigl, ${ }^{7}$ B.

* Logical Positivism, editado por Alfred Jules Ayer, The Free Press, Glencoe Illinois, 1959.

1 "Acaso sea la superior exactitud de la Física lo que atrae a muchas de las más rigurosas mentalidades de los filósofos analíticos (Carnap, Reichenbach, Russell, Schlick, para mencionar algunos nombres) a esta ciencia más que a las ciencias sociales." A. Pap, Elements of Analytic Philosophy, 1949, prefacio, pág. virr.

2 "Existe una dispersión muy heterógenea la que no puede ser abarcada mediante un nombre. Aun el nombre 'Escuela de Cambridge' no es exacto; me parece apropiado sólo en tanto que recuerda la parte que algunos profesores prominentes de Cambridge desempeñaron en la creación de una atmósfera filosófica, típica de nuestro tiempo." G. H. v. Wright, "Biographical Sketch", en la obra Ludwig Wittgenstein, de N. Malcolm, 1958.

3 Logical Positivism, ed. por A. J. Ayer, 1959, pág. 3.

4 F. Copleston, Filosofía contemporánea, 1958, pág. 25.

5 Ph. Frank, Modern Science and its Philosophy, 1955.

6 R. v. Mises, Positivism. A study in human understanding, 1951.

7 H. Feigl, "Logical Empiricism", en Living Schools of Philosophy, ed. por D: Runes' 1948. [215] 
Juhos, ${ }^{8}$ Ch. Morris, ${ }^{9}$ etc., y aun por críticos como Weinberg, ${ }^{10}$ Copleston, ${ }^{11}$ o Joad. ${ }^{12}$

En nuestro idioma, la literatura filosófica de esta corriente es lamentablemente escasa. Amén de que no hayan aparecido hasta esta fecha contribuciones personales, los textos e historias de la filosofía vertidos al español en forma sistemática la ignoran. ${ }^{13} \mathrm{El}$ año de 1945 marcó una etapa ya que en él fue publicada por primera vez la versión española de una obra de un positivista lógico: Entre la física y la filosofía de Philipp Frank. ${ }^{14}$

Algunas obras más han sido vertidas al español, pero hechas por distintas casas editoriales, sin un criterio rector, sin método y sin que por ello permitan formarse una idea cabal de los orígenes, modalidades y desarrollo de esta corriente.

Es conveniente apuntar los rasgos característicos de esta perspectiva filosófica, de este "positivismo lógico" en sentido lato y mostrar los que han permitido perfilar grupos o escuelas diversos, de los cuales no sería sino uno, el positivismo lógico en sentido estricto; después de esta descripción, resultará consecuente entender cómo el profesor Ayer ha incluido en su selección, ora a pensadores agrupados en las escuelas de Oxford (G. Ryle) o de Cambridge (F. Waismann), ora a pensadores más bien independientes que no han formado ni pertenecido a ninguna escuela en común, tales como Russell o Ramsey, y sin que por ello el conjunto pierda unidad o se aparte de los límites que el título establece.

La corriente de la que me propongo apuntar estas notas, la del positivismo o empirismo lógico en sentido amplio, o neo-positivismo crítico o filosofía analítica - que de todas estas y algunas maneras más ha sido denominada- exhibe caracteres que raras veces han aparecido en otros movimientos filosóficos.

No presenta a un pensador como creador único de un sistema total - desde sus primeras bases hasta sus más periféricas consecuencias. Esta tendencia tan acusada en el decurso del desarrollo filosófico, se acentúa fuertemente en el siglo XIX. En este sentido las escuelas filosóficas usuales, acostumbran separar un núcleo de problemas, de soluciones o incluso de puntos de vista, de aquellos que están aún en lo que podríamos llamar el proceso de creación. A los segundos puede criticárselos, pero no así a los primeros ya que en ellos radica lo fundamental de su postura. Este afán por excluirlos de toda crítica que pudiera depurarlos y mejorarlos, acaba por convertir lo que fuera pensamiento original, en un cuerpo dogmático que resulta adecuado, no para la reflexión filosófica, sino meramente para la contemplación mística.

En ocasiones he pensado que la causa relevante del decenso en importancia - Ia desaparición del escenario filosófico, de cuerpos doctrinarios que en su tiempo ejercieron extraordinaria fascinación, residió en esta ausencia de poste-

8 B. Juhos, "Principles of Logical Empiricism", Mind, 1937.

9 Ch. W. Morris, A Logical Positivism, Pragmatism and Scientific Empiricism, 1937.

$10 \mathrm{~J}$. R. Weinberg, An examination of Logical Positivism, 1936 (existe versión éspañola).

11 F. Copleston, Contemporary Philosophy, 1956 (existe versión española).

12 C. E. M. Joad, A critique of Logical Positivism, 1950.

13 Entre las historias de la filosofia, las únicas excepciones son: la obra de I. M. Bochenski, La filosofía actual (1949), y una mención breve en la obra de M. F. Sciacca, La filosofía, hoy. Hay una descripción en el artículo de J. Ferrater Mora "Las tres filosofías" (1957), y exposiciones y críticas en la obra de J. R. Weinberg, Examen del positivismo logico (1959), y en las de Risieri Frondizi, El punto de partida del filosofar (1945) y ¿Quéé son los valores? (1958). Las obras y artículos exclusivamente de crítica son bastante más numerosos.

${ }_{14} \mathrm{Si}$ se exceptúa Átomo y Cosmos de $\mathrm{H}$. Reichenbach exponente principal de la Escuela de Berlín; dicha obra trata de un tema concreto, es de carácter popular y no una exposición de su Escuela ni de la corriente en general. 
rior desarrollo, de avances y polémicas internas, de constante reexamen crítico, de disposición para incorporar dialécticamente las contribuciones de las vecindades más próximas, en suma, residió en un proceso protector de "liturgización" hacia enunciados dogmáticos.

Es posible advertir esta atrofia en algún sistema, pese a que perviva socialmente, aunque ya no por energía interna, sino apuntalado y sostenido por intereses institucionales.

En marcado contraste, la corriente que examinamos presenta los resultados de trabajos en equipo, que, dentro de un amplio radio de acción, se han extendido explorando las áreas de la sintaxis lógica, la condición de los lenguajes formalizados y de las disciplinas formales en general, del constante avance de la lógica simbólica, de la precisión de la semántica y la expurgación de las entidades es. púreas y sin sentido que la infestaban, de los fundamentos, conceptos y procedimientos de las ciencias empíricas, como la axiomatización del espacio y el tiempo físicos, de la definición y la explicitación de los conceptos científicos tales como los de verdad lógica, verdad semántica, causalidad, probabilidad, ley natural, medida, confirmación y grado de confirmabilidad de las hipótesis; de la axiomatización y de los fundamentos de las ciencias formales y de las ciencias fácticas, de la técnica de la construcción de una teoría, de los significados emotivos en moral o en estética, de los numerosos análisis lingüísticos, sea de términos de las ciencias o de la vida diaria y otros aspectos más; tales exploraciones, repito, no han pretendido ser realizadas por un solo investigador, sino que un conjunto de ellos han incidido en un solo campo o en algunos cercanamente relacionados. A treinta años de'desarrollo, puede ya apreciarse su fecundidad teórica y la amplitud geográfica resultante del número de sus adherentes.

El panorama así existente acaso pudiera desorientar a un observador poco experimentado; no se aprecian esos enérgicos trazos centrales cuyas direcciones anuncian el advenimiento de un sistema completo. Se advierte por el contrario la presencia de numerosos análisis de tipo local, en los que más que la pretensión de encajar como pieza esencial de una estructura, existe sólo el propósito circunscrito de analizar un específico problema, pero de analizarlo con una severidad y un rigor lógicos en el grado posible, exhaustivos. Esta severidad y este rigor lógicos constituyen el método que, propiamente, nos permite hablar de una escuela, de una filosofía común, y no es otro sino el del análisis lógico.

Los equipos de trabajo así constituidos, "tendencias dentro de las "escuelas" " si deseamos recurrir a la terminología usual, ayunos de rasgos de originalidad espectacular, han estado dispuestos a y deseosos de heredar y aprovechar lo que a través de la tradición filosófica y en mayor grado del Renacimiento a nuestros días, resulte elemento incorporable a las tareas señaladas del análisis lógico; este propósito se halla explícitamente establecido en Die Wissenschaftiche Weltauffassung; der Wiener Kreis y el profesor Ayer lo comenta en el estudio introductorio a la obra diciendo que "... los autores establecen una lista de aquellos a quienes consideran como sus principales precursores. Como empiristas y positivistas designan a Hume, a los filósofos de la Ilustración, a Comte, Mill, Avenarius y Mach; como filósofos de la ciencia, a Helmholtz, Riemann, Mach, Poincaré, Enriques, Duhem, Boltzmann y Einstein; como lógicos tanto de la lógica. pura como de la aplicada, a Leibniz, Peano, Frege, Wittgenstein, Schröder, Russell, Whitehead; como axiomatistas a Pasch, Peano, Vailati, Pieri y Hilbert; y como moralistas y sociólogos de temperamento positivista a Epicuro, Hume, Bent. ham, Mill, Comte, Spencer, Feuerbach, Marx, Müller-Lyer, Popper-Lynkeus y Carl Menger el Viejo. 
"La lista es sorprendentemente amplia, pero debe recordarse que, en la mayor parte de los casos, se toma en consideración solamente un aspecto especial del trabajo de los autores. Así, se incluye a Leibniz por su lógica, no por su metafísica; Karl Marx no es incluido ni por su lógica ni por su metafísica, sino por su acercamiento científico a la historia. Si excluimos de nuestra lista a los contemporáneos. .." 15

Sumariamente puede decirse que las tradiciones vigorosas que incidieron en el surgimiento del pensamiento del empirismo lógico, fueron (I) la tradición empírica y dentro de ella y en grado mucho mayor que el resto, los pensamientos de Hume y Mach; (II) el esclarecimiento y la rigorización de la matemática que, iniciada por Leibniz, culmina, por una parte, con el trabajo rigurosamente formalizado de una ciencia, en la obra de Hilbert, por otra, en la obra nuclear de la lógica simbólica contemporánea, los Principia Mathematica y que en un tercer aspecto va forjando, primero con Peano y Frege y más tarde con Russell, el más valioso instrumento metodológico: el análisis lógico; (III) la labor de investigación y técnica científica de Boltzmann, Helmholtz, Mach y Einstein y (IV) finalmente, no mencionada por Ayer en razón de la declaración de excluir a los contemporáneos, la singular labor de Ludwig Wittgenstein cuya innegable influencia es bien clara en el Círculo de Viena, en la Escuela de Cambridge y en la Escuela de Oxford. Wittgenstein fue parcialmente aceptado y parcialmente rechazado, pero tanto la forma positiva como la negativa, hubieron de ser fundadas y dieron origen a diversas obras. El enfoque hacia la importancia del estudio del lenguaje para los problemas filosóficos, es principalmente labor que se debe a Wittgenstein.

La historia detallada de la aparición y el desenvolvimiento de este movimiento. es tarea aún por ejecutar; el realizarla deberá mostrar - aparte de las grandes corrientes pretéritas cuyos resultados heredan y que apuntamos en líneas anteriores- el orden, ora sucesivo, ora simultáneo, de aparición y el modo como unos grupos fueron influyendo en los otros o como personalidades aisladas, aun sin constituir proselitismo, tuvieron gran influencia en los grupos que posteriormente aparecieron.

Aún el mero esquema de este desenvolvimiento concomitante o sucesivo de idearios filosóficos, quedaría fuera de ligar y de los límites estrechos de una crónica. El profesor Ayer, atendiendo a su localización y con un criterio amplio, menciona diez agrupaciones distintas. ${ }^{16}$. Desearía sugerirle la inclusión de algunas, respecto de quienes no encuentro razones para excluir, ${ }^{17}$ Arthur Pap ha

15 A. J. Ayer, Logical Positivism, 1959, pág. 4.

16 El Círculo de Viena. La Escuela de Berlín. Los filósofos escandinavos (Dinamarca y Noruega). La Escuela Empirista de Upsala. La Escuela Holandesa. Los Lógicos de Münster. El grupo de lógicos norteamericanos. La escuela analista de Cambridge. El grupo polaco de Lwow y de Varsovia y la Escuela de Oxford.

17 I. Los adherentes franceses: L. Rougier, E. Vouillemin, M. Frechet, M. Boll, A. Rey.

II. Chang Shen-fu, más cercano al pensamiento de Russell que al Círculo de Viena.

III. Hung Ch'ien, constante expositor de la Escuela de Viena.

Wang Hsien-chün, trabajos sobre lógica.

Hu Shih-hua, trabajos sobre lógica

Hung Ch'ien, estudios sobre M. Schlick y R. Carnap.

Fung Yu-lan, estudios generales sobre empirismo lógico.

IV. Ishimoto, Lógica modal.

Sawai, Análisis lógico.

Yamada, Etica.

Aomi, Ciencias sociales.

Takeda, Lenguaje de la quimica. 
establecido cuatro sectores, atendiendo a la naturaleza de la especialización de sus estudios. ${ }^{18}$

El compilador de Logical Positivism tomó de algunas escuelas (hubiera sido imposible hacerlo de todas) los estudios más característicos o los que consideró más característicos, ya que es sabido que en estos menesteres se descansa, en última instancia, en el subjetivo criterio de quien los realiza.

Con indudable acierto incluye en primer término un trabajo de B. Russell, "Atomismo lógico". Fue Russell el primero que logró la reunión de las tradiciones que anoté líneas antes; por una parte la tradición empírica, pero constantemente puesta a prueba y depurada al relacionarla con el cuerpo cambiante y progresivo de la ciencia a través de sus más variadas facetas, por la otra los trabajos de formalización y análisis logrados en lógica y en matemática. El análisis lógico preconizado por Frege y que va a constituir más tarde el método unánimemente aceptado por el empirismo lógico, fue en realidad incorporado a los estudios filosóficos por Russell.

A continuación el libro contiene, bajo el rubro de "Filosofía, metafísica y significado", cuatro artículos, dos de Moritz Schlick a quien usualmente se reconoce como fundador del Círculo de Viena, "El cambio de dirección en la filosofía" y "Positivismo y realismo", uno de Rudolf Carnap, "La eliminación de la metafísica a través del análisis lógico del lenguaje" y el cuarto debido a Carl G. Hempel, "El criterio empirista de significado".

Probablemente el área del saber en donde más amplios resultados ha cobrado el análisis lógico es en la semántica; sus investigaciones sobre el significado, bien sea de los enunciados, bien de los términos, le ha permitido enjuiciar a la metafísica con procedimientos con los que nunca fue analizada con anterioridad. Como consecuencia de ell ${ }_{0}$ la conotación del concepto de la filosofía queda enérgicamente transformada.

Honke, C. I. Lewis.

Nagai, R. Carnap.

Koizumi, C. L. Stevenson.

Fukukama, La semántica de Dewey.

Isono, La teoria del valor de Dewey.

Uyeda, La filosofía de Dewey y el positinismo lógico.

Los títulos colocados a continuación de las personas en la sección $\Gamma^{n}$ son los de los trabajos con los que cada uno colaboró en el Curso de Seminario llevado a cabo en la Universidad de Tokio en 1953, bajo la dirección del prof. J. D. Goheen.

18 "Sin pretender una precisión histórica absoluta, podría distinguir las siguientes fracciones.

1) Los seguidores de Carnap, quienes practican la construcción de lenguajes formalizados ideales, en los que los conceptos básicos (como 'consecuencia lógica', 'grado de confirmación', 'verdad'), comunes a todas las ciencias permiten definiciones exactas.

2). Los seguidores de G. E. Moore que enfocan su atención casi exclusivamente sobre el lenguaje del sentido común e insisten en que la condición primaria que debe satisfacerse es la conformidad con el 'uso común' mediante el análisis lógico de un concepto.

3) Los contimuadores de Wittgenstein o positivistas terapeutas, para quienes la filosofía no es una disciplina deseosa de algún género de conocimiento o descubrimiento intelectual, sino un método para revelar las confusiones lingüísticas que surgen a través de los "problemas" filosóficos y para la resolución de dichos problemas, mostrando cómo no tienen carácter genuino.

4) Filósofos que están encaminados hacia la clarificación de los fundamentos de las ciencias y más aún del conocimiento en general, mediante pacientes y detallados análisis pero que actúan 'independientes' y rehusan su incorporación a cualquiora de las facciones mencionadas." A. Pap, Elements of Analytic Philosophy, págs, $\mathrm{x}$ y x. 
"Lógica y matemática", el tercer capítulo, contiene dos artículos: el primero de Carnap nuevamente. "La lógica antigua y la nueva", y el segundo de Hans Hahn "Lógica, matemática y conocimiento de la realidad". En el primero, Carnap precisa el carácter metodológico de la lógica, los aspectos nuevos que presenta en su desarrollo en el presente siglo, su carácter simbólico, el modo como pudo determinar la estructura y resolver las antinomias lógicas tradicionalmente existentes, el grado especifico de la matemática con respecto a la lógica, el carácter tautológico de la lógica y las posibilidades de la unidad de la ciencia. En el se. gundo, el tema básico es el carácter tautológico de la lógica y de la matemática como disciplinas formales y consecuentemente muestra la inconsecuencia de determinadas teorías empíricas y aprioristas. Del artículo original en la versión inglesa fueron suprimidos los dos últimos parágrafos.

"Cónocimiento y verdad", el cuarto capítulo, presenta algunos aspectos im. portantes de la lucha por el "fisicalismo", el lenguaje unitario de la ciencia y consta de cuatro artículos. El primero, de Carnap, "Psicología en lenguaje físico" (acaso "fisical" fuera más exacto que físico); el segundo, de Otto Neurath, "Oraciones protocolares"; el tercero, nuevamente de Schlick, "El fundamento del conocimiento" y el cuarto del propio Ayer "Verificación y experiencia". El profesor Carnap muestra la posibilidad de proyectar el físicalismo al campo de la psicología, en tanto que Neurath plantea cómo un empirismo consecuente sólo puede sostenerse establecido sobre este tipo de enunciados, los protocolares, los que directa e íntimamente toman contacto con la experiencia. El artículo de Schlick marcó (en unión con un artículo aparecido anteriormente y debido a Ramsey) el principio de una verdadera polémica interna en la que participaron, además de los anotados, Hempel, Ayer y en cierto modo indirecto, Strawson. El artículo de Ayer constituye un examen de algunas de las teorías de la verdad empirica, lo que le lleva a fijar su propia posición, no coincidente con Carnap ni con Neurath y a exhibir el carácter de las proposiciones básicas, proposiciones a las cuales ya habia dedicado algún estudio especial. ${ }^{19}$

En el capítulo v, "Ética y sociología", aparecen tres artículos: "¿Qué es lo propio de la ética?" de Schlick, "El significado emotivo de los términos éticos" de Stevenson y "Sociología y fisicalismo" de Neurath. EI artículo de Schlitk, que es el primer capítulo de su bien conocido libro Problemas de la ética, es un capitulo de planteamiento, de cómo la ética no tiene un carácter epistemológico, ni esa impenetrabilidad que tanto sorprendía a Moore, ni el carácter formal que pretendió el criticismo. La condición básicamente emotiva de la ética, que ya había sido apuntada certeramente por Ogden y Richards, es desarrollada en el artículo de Stevenson y, en el último, Neurath insiste en su propósito de la unidad de la ciencia, mostrando la traducibilidad de la sociología al lenguaje fisicalista.

El capítulo vi y último es una concesión a corrientes y personas vecinas al Círculo de Viena. El primer artículo "Filosofía" constituye un justo merecimiento a su autor Franck Ramsey, quien no pudo darnos sino las primeras muestras de su gran calidad, ya que murió a los 26 años y sólo las preocupaciones de $R$. $B$. Braithwaite pudieron rescatar en volumen unitario, Los fundamentos de la matemática, los estudios y artículos que de otra manera hubieran acabado por desaparecer. Los puntos de vista de Ramsey de que la filosofía es un sistema de definiciones 0 , más ampliamente, un sistema de descripciones de cómo pueden establecerse dichas definiciones, van a reflejarse más tarde en las escuelas inglesas contemporáneas.

19 A. I. Ayer, "Basic Propositions", en Philosophical Analysis, ed. por M. Black. 
Gilbert Ryle, el conocido editor de Mind, es él autor del segundo artículo, "Argumentos filosóficos". Éste es el conjunto de reflexiones que en torno a la labor de R. G. Collingwood, hizo en su Lección de Apertura en Oxford en 1946. El autor examina la estructura lógica de los argumentos usualmente utilizados en filosofía y con especial cuidado la reductio ad-absurdum.

En "Cómo veo la filosofía" el profesor Friedrich Waismann, colaborador de Erkenntnis desde los primeros días muestra radicalmente sus puntos de vista analíticos; la filosofía difiere completamente de la ciencia o de cualquier otro género de actividad análoga, no sólo porque le son ajenos sus problemas, sino porque su actividad es puramente metodológica. Sus problemas auténticos no residen en dar respuesta a un problema dado, sino en encontrar el sentido de éste.

En las líneas siguientes trataré de exhibir el contenido de algunos artículos, de tres o cuatro, ya que es posible que para el lector resultara un poco fatigosa la caminata a través del resumen de los dieciocho (incluido el de introducción) que constituyen el volumen.

\section{B. RUSSELL}

El maestro Bertrand Russell influido por Moore en su rechazo del idealismo, pronto se aparta de aquel para tomar un rumbo propio. Es tan copiosa la producción de Russell y tantos los temas hacia los que ha orientado su extraordinaria inteligencia, que su sola enumeración resultaría insólita. Me limitaré pues a anotar aquellos aspectos que mejor sirvan a mis propósitos de señalar sus influencias dentro del contexto del empirismo lógico.

1) Recoge la idea central de la Characteristica Universalis de Leibniz y los trabajos que le siguieron hasta tomar forma definida, en el siglo pasado, en los intentos de un "álgebra de la lógica"; por la otra parte los análisis, tanto de Peano como de Frege, relativos a la reducción de la aritmética a los términos de la lógica, permitieron la formulación, primero, de The Principles of Mathematics (hay versión española, 1948) y más tarde de los Principia Mathematica. Estas obras influyeron en el desarrollo de la logística por la Escuela Polaca (Varsovia y Lwow) y de la misma logística por el Círculo de Viena.

2) El desarrollo del tema del análisis lógico como método de investigación, que ya había sido apuntado por Frege; esta actitud metodológica se presenta como el dato más constante a través de todas las tendencias o grupos que bajo su influencia, cercana o no, se desarrollan posteriormente.

3) La obra epistemológica de Russell ha sufrido constantes transformaciones; el mejor resumen de la misma es el que consigna en su penúltimo libro My Philosophical Development (1959). La doctrina del atomismo lógico fue elaborada y sostenida de 1900 a 1925 y expuesta, entre otros, en tres artículos publicados en The Monist en 1918 bajo el título de "The Philosophy of Logical Atomism" y en su ensayo para el libro editado por el profesor J. H. Muirhead $;^{20}$ este ensayo intitulado "Logical Atomism", es el que figura como primer artículo en la selección del profesor Ayer.

\section{Atomismo lógico}

"Atomismo lógico" no es un ensayo redactado de un modo austero y sistemático, sino a manera un tanto de confesión de la evolución filosófica del autor.

20 Contemporary British Philosophy, ed. por J. H. Muirhead, 1924. 
1. El propósito es medularmente metodológico. Mostrar cómo "la actividad de la filosofía, como yo la concibo, es esencialmente la del análisis lógico, seguido por la sintesis lógica".

2. El desengaño del idealismo le llevó a una inquisición inicial sobre la posibilidad de encontrar conocimientos sólidamente fundados; esta inquisición lo condujo al campo de la matemática.

3. El desarrollo matemático ha corrido sobre dos cauces paralelos aunque no sincrónicos: las ideas de la matemática y las ideas sobre la matemática: las primeras han sido elaboradas merced a verdaderos análisis lógicos de la matemática y en este sentido se ha realizado una auténtica tarea fílosófica, aunque a sus autores no se les haya denominado como tales y la segunda frecuentemente ha obtenido conclusiones que muestran un verdadero rezago o un desacuerdo amplio con los resultados de la primera.

4. Así, mientras la labor de los geómetras no euclideanos mostraba la posibilidad alternativa de sostener uno u otro sistema geométrico formal como posiblemente válido para la realidad empírica, en filosofía se proponía la validez universal $\mathrm{e}$ incontrovertible de la geometría euclideana a través de un pretendido carácter de forma a priori de la sensibilidad; análogamente, mientras se mantenía el dato de la continuidad como propiedad indiscutible del tiempo, del espacio y del - movimiento -dato en realidad importado de la vida cotidiana y del sentido común- Weierstrass descubría, merced al análisis del cálculo, del que excluía la noción de infinitesimal, su verdadero carácter discontinuo; los análisis de Cantor sobre la teoría de los conjuntos, liberaron al pensamiento de algunas de las antinomias que aparecen, tanto en la obra de Kant como en la de Hegel. Más tarde Frege, al mostrar cómo toda la aritmética puede deducirse de la lógica pura y cómo puede desarrollarse como un mero sistema deductivo, a partir de un conjunto fijo de premisas, invalida el supuesto carácter sintético a priori de sus enunciados.

5. Russell, con la colaboración de Whitehead, amplió las relaciones de dependencia ya establecidas para la aritmética con respecto a la lógica, a toda la matemática y se enfrentó a los problemas de las paradojas que hasta entonces parecian constituir un verdadero mentís a la validez y estructura de la lógica toda.

6. A continuación presenta el autor una síntesis de su "teoría de las descripciones" y de su "teoría de los tipos" las que le permitieron expurgar a la lógica de multitud de falacias y de las pretendidas paradojas; la primera puede considerarse el antecedente de lo que en Carnap va a constituir la sintaxis ló. gica. La segunda mostró la solución lógica de paradojas antiguas, como la del cretense mentiroso Epiménides, o modernas, como la del carácter del conjunto de los conjuntos heterológicos.

7. Más tarde considera el problema del desarrollo del lenguaje y su exacta correspondencia o no con el orden de los hechos. Modalidades en la estructura lingüística de las proposiciones, nos han llevado descuidadamente a suponerlas corresponder con exactitud a modalidades del mundo de los hechos; esto, en ocasiones, es sólo parcialmente válido; en ocasiones, los moldes lingüísticos resultan continente realmente estrecho para la pluralidad de los hechos.

8. Como consecuencia, apunta el valor y la urgencia de formar un lenguaje lógico ideal. La posibilidad de estos lenguajes ha sido desarrollada, primero, a través de las páginas de los Principia Mathematica; más tarde en el Círculo de Viena, por una parte, en la teoría del fisicalismo y, por la otra, en las teorías de la formalización de los lenguajes, labor en la que Carnap obtuvo la colaboración crítica de los lógicos polacos, de Tarski en especial, 
9. El filósofo concluye su estudio, mostrandó cómo el análisis lógico entrega datos susceptibles de ser reunidos en una posterior síntesis lógica y, a modo de ejemplo, presenta un esquema de lo que, a título de hipótesis, pudiera ser examinado como nominación de la estructura del mundo.

Las ideas examinadas dan cuenta de por qué Ayer incluyó -en un estudio sobre positivismo lógico- a Russell. Con anterioridad J. Joergensen había hecho algo análogo al estudiar en un capítulo de The Development of Logical Empiricism lo que llamó "The Logical Positivism of Bertrand Russell" págs. 11-17. Russell, sin embargo, ha criticado la obra del Círculo de Viena en An Inquiry into Meaning and Truth (1940), Human Knowledge (1948) y Logical Positivism (1950).

\section{Rudolf Carnap}

El profesor Carnap es uno de quienes participan en el Círculo de Viena desde su iniciación. En estrecha cooperación de ideas con Schlick, Neurath, Hahn y Frank acepta, a instancias del primero, cátedra en Viena en 1926 y participa, en colaboración con Neurath y Hahn, en la redacción de Die Wissenschaftliche Weltauffassung; der Wiener Kreis. Su producción de cerca de 20 obras y numerosos artículos, ha cubierto temas de sintaxis lógica, semántica, lógica simbólica, etc. Nada de ella está vertida a nuestro idioma.

"Überwindung der Metaphysik durch logische Analyse der Sprache" apareció en Erkenntnis en el segundo año de labores del Círculo de Viena y dos años más tarde fue vertida al francés, en edición revisada y puesta al día por el autor y en la que aparece bajo el rubro de" "La Science et la Métaphysique devant l'Analyse Logique du Langage".; en Logical Positivism la versión inglesa tiene el título de "The Elimination of Metaphysics Through Logical Analysis of Language".

\section{La eliminación de la metafísica a través del análisis lógico del lenguaje}

Conclusión: Los pretendidos enunciados de la metalisica son asignificativos.

1. Los críticos de la metafísica han sido numerosos, mas el enfoque actual no tiene antecedentes, en virtud de que hasta antes de ahora se careció de los métodos analíticos de investigación que propórciona la lógica moderna.

2. El estudio del significado de las palabras _-dentro de un lenguaje definido- nos muestra que mientras algunas de éstas lo poseen, otras sólo aparentan poseerlo.

3. La inquisición sobre el significado de una palabra, se realiza colocándola dentro de su oración elemental e inquiriendo sobre sus relaciones de deductibilidad, sus condiciones de verdad, el grado de su verificabilidad y sólo así, finalmente, podremos responder sobre su significado.

4. Cuando un enunciado contiene palabras asignificativas, deviene enunciado asignificativo; se le denominará pseudo-enunciado.

5. Cuando una secuencia de palabras está articulada faltando a la sintaxis gramatical, deviene pseudo-enunciado.

6. Cuando una secuencia de palabras está articulada faltando a la sintaxis lógica, deviene pseudo-enunciado.

7. El examen de los "enunciados metafísicos" muestra su falta de sentido, sus violaciones a la sintaxis lógica. 
8. Como consecuencia de lo anterior, están imposibilitados de mostrar un criterio de verificabilidad y son, por ende, asignificativos.

9. La pretensión de hallarse supuestamente situados por encima de cualquier posibilidad de verificación empírica, les da "ipso facto" este carácter de asig" nificativos; la pretensión, en alguna metafísica empírica, de ser verificada, la colocaría de inmediato en el orden no meta-físico sino físico de las ciencias fácticas.

10. Los enunciados metafísicos no son, sin embargo, vacuos en su totalidad. $\mathrm{El}$ análisis sintáctico muestra su completa carencia de significado designativo, pero las imágenes y los sentimientos frecuentemente asociados con ellos, dan razón de su significado expresivo.

11. El significado expresivo de estos enunciados, da muestra, en forma inmediata, de la situación emocional del escritor $y$, en forma mediata, de su actitud frente a la vida, de su W eltanschauung.

\section{Carl Gustav Hempel}

Graduado en la Universidad de Berlín, aparece originalmente como miembro de la llamada "Escuela dê Berlín" o "Escuela de Filosofía Científica" de la que $H$. Reichenbach se presenta como el conductor visible. En los tiempos originales del Círculo de Viena, seguramente esta Escuela es la más estrechamente ligada a ella $\mathrm{y}$, en muchos aspectos, acaso no puedan discernirse límites de separación exacta. En el artículo seleccionado, que originalmente se publicó con el nombre de "Problems and Changes in the Empiricist Criterion of Meaning", el autor establece las etapas por las cuales ha pasado este criterio y concluye en proposiciones análogas a aquellas preconizadas por Carnap en "Testability and Meaning".

\section{El criterio empírico de significado}

\section{Aspecto general y operaciones preliminares:}

1. La postura directriz del empirismo moderno radica en el enfoque de que todo conocimiento no-analítico se basa en la experiencia.

2. Una oración sólo puede ser declarada o verdadera o falsa, si hace una aseveración significativa cognoscitivamente.

3. Una oración hace una aseveración significativa cognoscitivamente solamente si, (a) es analítica o auto-contradictoria, o (b) si es capaz, en principio, de comprobación experimental.

4. De acuerdo con este criterio empírico de significado cognoscitivo, muchas de las formulaciones de la metafísica tradicional y grandes partes de la epistemo* logía, se hallan desprovistas de significado cognoscitivo, independientemente de la riqueza emotiva o inspiración moral que contengan.

5. Similarmente, determinadas doctrinas localizables dentro de la ciencia empírica muestran, al ser examinadas, hipótesis incapaces de comprobar su origen en datos observables; consecuentemente se calificará a tales afirmaciones como pseudo-hipótesis; es posible aplicar este juicio a especulaciones neo-vitalistas en torno a entidades tales como la "entelequia" o a las "hipótesis telefinalistas" propuestas por Lecomte de Noüy.

6. A (3-b) la llamaremos oración con significado empírico.

7. El concepto de comprobación, que tanta importancia tiene, ha ido mejorando en precisión, a través de sucesivos análisis sobre la estructura del conocimiento empírico.

8. Es necesario distinguir tres conceptos de la mayor utilidad: a--característica observable; b.-predicado de observación y c.-oración de observación. 
9. Se llamará "característica observable" a aquella propiedad o relación de los objetos físicos de la que, bajo condiciones/adecuadas, mediante la observación directa puede asegurarse su presencia o ausencia. Quédan comprendidos en esta clase, términos tales como "verde", "blando", "líquido", "mayor que", y excluidos términos tales como "bivalente", "carga eléctrica" etc.

10. Llamaremos "predicados de observación" a aquellos términos que se refieran a características observables.

11. Llamaremos "oraciones de observación" a aquellas que - correcta o incorrectamente- aseveren, respecto de determinado o determinados objetos, que poseen -o carecen de- determinadas características de observación. Denominaremos así a oraciones tales como "La Torre Eiffel es más alta que los edificios de su vecindad".

\section{Elapas sucesivas del concepto de comprobacion:}

12. (Primera tesis.) Inicialmente (en los días del Círculo de Vienta) se decía de una oración que tenía significado empírico si era capaz, por lo menos en principio, de una verificación completa mediante la evidencia observacional, es decir, si mediante la descripción de la evidencia observacional, se podía establecer conclusivamente la veracidad de la oración.

13. Técnicamente planteado: Una oración " 0 " tiene significado empíricó si, y solamente si, es posible señalar un conjunto finito de oraciones $0_{1}, 0_{2}, \ldots, 0_{\mathrm{n}}$ tal, que si los elementos de este conjunto son verdaderos, " 0 " es necesariamente verdadero también.

14. (Otra tesis). Exigencia de completa verificabilidad, en principio. Se dice que una oración tiene sentido empírico si, y solamente si, no es analítica y se sigue lógicamente de una clase de oraciones de observación, finita y consistente lógicamente.

15. (Otra tesis). Exigencia de completa falsificabilidad, en principio. Una oración tiene significado empírico si, y solamente si, su negación no es analítica y se sigue lógicamente de alguna clase lógicamente consistente de oraciones de observación.

16. (Otra tesis). Una oración tiene sentido empírico si, de su conjunción con una hipótesis subsidiaria adecuada, es posible derivar oraciones de observación que no son derivables de la hipótesis subsidiaria aislada.

17. (Otra tesis). Como mera modificación de la anterior, restringe el carácter de la oración subsidiaria a oraciones, o analíticas, o que independientemente muestren su capacidad de comprobabilidad en el sentido del criterio modificado.

18. (Otra.tesis). Traducibilidad a un lenguaje empírico. Una oración tiene significado empírico si, y solamente si, es traducible a un lenguaje empírico. Entendiendo por este último, un lenguaje correctamente construido, con su vocabulario y reglas para la formación de oraciones, lógicamente establecido. (Véase punto octavo del resumen del artículo de Russell.)

Hempel, después de analizar las tesis expuestas, muestra su decidida preferencia por esta última, no sin indicar, con gran honestidad, que, en su conjunto, las soluciones apuntadas pueden ser suceptibles de un mejor desarrollo posterior.

\section{Charles Leslie Stevenson}

Profesor de la Universidad de Michigan posee títulos de las universidades de Yale, Cambridge y Harvard; puede considerarse colocado un poco margi- 
nalmente respecto del empirismo lógico. La "teoría emotiva" apuntada por Ogden y Richards y suscrita también por Carnap, Ayer, Barne, tiene seguramente su más amplia exposición en Ethics and Language de Stevenson, pero no estoy seguro de que, en los términos en que está formulada, tuviera la aceptación general de los empiristas lógicos y ello no obstante de que sobre "The emotive meaning of ethical terms" Pap opina que se trata de "... probablemente el más célebre enunciado" (de la teoria emotiva).

\section{El significado emotivo de los términos éticos}

El problema y el método de análisis:

1. Los problemas éticos surgen en la forma: ¿Es bueno esto y aquello? o ¿Es mejor esta alternativa que aquella?

2. Trataremos de esclarecer qué quiere decir "bueno" en esta o análogas expresiones, bien mediante la definición de los términos, o a través de algún otro método que nos parezca también eficaz.

3. Trataremos de reemplazar la palabra "bueno" por un conjunto de términos que lo definan. Hay que establecer la condición que debe satisfacer este reemplazamiento.

4. Debe satisfacer la condición de expresar por medio de la definición, todo aquello que hemos querido expresar cuando hemos hecho uso del término definido: llamaremos a esta condición, relevante.

5. La condición anterior pues, permitirá que en ningún caso sea necesario el uso de la palabra definida; si esta situación se satisface, pero no siempre, concluiremos que es relevante, pero no total sino parcialmente relevante y que debe ser completada. (En el uso confuso y ambiguo de las palabras en el lenguaje ordinario, con gran frecuencia se encuentra que se den distintos significados a un término, no sólo - como más tarde veremos- en correspondencia al plano descriptivo y al dinámico, sino aun en un mismo plano.)

\section{Soluciones apuntadas:}

6. La palabra "bueno" ha sido definida en términos de "aprobación" o actitudes psicológicas similares; Hobbes considera qué es lo que es "deseable por mi": Hume aquello que "es aprobable por la mayoría de la gente". Éstas y teorías similares podrían nominarse bajo el rubro común de "teorías de interés".

7. El análisis hecho en el artículo, muestra que ninguna de estas tesis es totalmente relevante.

8. Es posible considerar una teoría del interés más, que pudiera formularse por este tenor: " $\mathrm{X}$ es bueno" significa que la mayoría de la gente aprobaría a $\mathrm{X}$ si conociera su naturaleza y sus consecuencias". La crítica muestra que tampoco aparecería como totalmente relevante.

9. Las teorías tradicionales del interés, han establecido que los enunciados éticos son descriptivos de un estado de interés existente y que a ellos solamente compete dar información respecto a estos intereses y es posible que el énfasis en esta modalidad descriptiva, informativa, sea el que le imprima ese carácter de relevancia incompleta. Pero el propósito principal de un juicio ético no es aquél, sino el de crear una influencia. No el de la descripción de los intereses de la gente sino el de la creación de un estímulo que influya en su actitud. Estos juicios sugieren, recomiendan, impelen, al interés respecto a un objetivo, más que asentar el que estos intereses ya existieran. 
10. Si atendemos a la presentación de los juicios éticos, deberemos atender precedentemente a los usos que se da al lenguaje. En ocasiones éste se usa para asentir, establecer, comunicar hechos o relaciones. En otras para expresar nues. tros sentimientos y emociones, crear ese tipo especial de emoción llamado a veces "feeling" estético o para estimular al auditorio para determinadas acciones o actitudes, como en la poesía. Al primer uso lo llamaremos "descriptivo" y al segundo "dinámico".

11. Dentro del área dinámica, los enunciados pueden cobrar diversos significados. El significado es referible a la tendencia hacia la cual el sentido general del enunciado se refiere.

12. Algunas oraciones con significado emotivo dentro del uso dinámico, portan juicios éticos. Pueden caracterizarse cuando al decir "Esto es bueno" hay una referencia hacia los intereses favorables al que habla y al auditorio y cuando este significado emotivo placentero sugiere una actitud y frecuentemente una acción. Pero esto está lejos de referirse a un simple deseo cualquiera; exige una peculiar suerte de aprobación. "Cuando una persona quiere algo, siente agrado cuando lo logra y descontento cuando no. Cuando una persona aprueba moralmente algo, experimenta una rica sensación de seguridad cuando lo logra y queda indignada, aturdida, cuando no". Y esta típica emoción traduce el carácter ético de los juicios que pueden exhibirla.

\section{Hans Hahn}

Matemático, colaborador inicial del Círculo de Viena, corredactor de Die Wissenschaftliche Weltauffassung; der Wiener Kreis (La concepción científica del mundo del Círculo de Viena) fallece tempranamente, en 1934, y no deja sino artículos dispersos en revistas, sobre temas de lógica, matemática y crítica del conocimiento. ${ }^{21}$

\section{Lógica, matemática y conocimiento de la realidad}

1. Existen en física dos órdenes de enunciados: a) aquellos que provienen de una observación directa hecha por los sentidos, por ejemplo: "Si se hace vibrar una cuerda tensa, se escucha un sonido" y b) aquellos establecidos mediante consideraciones teóricas, por ejemplo: "Existe amoniaco en la atmósfera de Júpiter".

2. Esta situación no es privativa de la física, sino común a todo el orden científico que no es sino uno, y nuestro enfoque hacia la física se debe a la circunstancia de ser éste el sector mejor estudiado.

3. De un modo inicial, común y $\sin$ pretensión de rigor crítico, se podría decir que existen dos medios, merced a los cuales entendemos la realidad: o a través de reiteradas "observaciones", "experiencias", o mediante "el pensamiento".

4. La corriente racionalista, de gran amplitud, en ocasiones radical, en otras atenuada, ha dominado el pensamiento filosófico desde Grecia hasta nuestros días. A través de ese largo período de especulaciones, muestra, en su conjunto, una fecundidad verdaderamente modesta.

5. La corriente empírica, surgida realmente en Inglaterra contó, para sus tesis, con el aporte que el constante desarrollo de las ciencias naturales le brindaba; pero pronto se encontró con que, a diferencia del acusado carácter con-

21 El único trabajo de Hahn vertido a nuestro idioma es un artículo "La crisis de la intuición", publicado por la Revista de Occidente, tomo XLIII, $\mathrm{n}^{p}$ 129, pág. 314. 
tingente de las observaciones empíricas, los enunciados de la lógica y sobre todo de la matemática mostraban relaciones de carácter necesario, invariable, lo que significa serio obstáculo para suponerlas inferidas de la experiencia. El hecho se agudizaba al considerar la condición apodíctica, de inconcebibilidad de lo contrario de los enunciados matemáticos. Al pretender derivar las proposiciones matemá. ticas de la experiencia, aun cuando se asegurara que esta derivación fuera localizable en muy pretéritas épocas, éstas debían llevar consigo, al emigrar hacia su campo autónomo, el carácter contingente del primero o debería hallarse razón satisfactoria para despojarlas de ese carácter y poder conferirles su condición apodíctica. Ninguna de las dos hipótesis encontró razones plausibles para sostenerse.

6. Como una solución conciliatoria, se formuló el dualismo, el cual preconizó que en realidad ambos senderos eran fuente legítima de conocimiento y que, además, resultaba condición indispensable el concurso de ambos, ya que mientras la lógica y la matemática proveían los principios y leyes más generales, la observación entregaba el material que se ajustaría a dichas formas pre-existentes, para constituir el saber.

7. No hubo unidad de criterio respecto a los límites de las respectivas esferas de acción y mientras algunọs dieron a la geometría un carácter a priori, otros la consideraron derivada de la experiencia, hubo también quienes sostuvieron el carácter empírico de las leyes naturales, opinión que creció en seguridad al extrapolar a órdenes fuera de la observación directa, sea por su carácter macro o microscópico, las leyes sostenidas en el orden observable y obtener resultados satisfactorios.

8. La idea de un principio regulativo sobre el que corrieran los datos de la observación, a efecto de crear una estructura que tuviera exacta correspondencia con el orden de los hechos, parecía obligar a una hipótesis de armonía pre-esta- . blecida, de carácter místico y teológico en última instancia.

9. En ocasiones se pretendió definir a la lógica como la ciencia más amplia, la que estudiara a todos los objetos. Si consideramos la imposibilidad de conocer todos los objetos, resultará incapacitada para ninguna consideración sistemática y menos para exhibir certeza en sus enunciados.

10. "Contrariu sensu", se considera que la lógica no se ocupa de los objetos, sino exclusivamente del modo como hablamos de los objetos.

11. Aclarando: supongamós que distinguimos una serie de plantas en que se dan ciertas características y decimos: a estas plantas las vamos a denominar "rosa de las nieves", también las vamos a llamar "elébora negra" y luego concluimos que toda rosa de las nieves es una elébora negra. Reflexionemos y veremos que este enunciado es universalmente cierto y también que no estamos diciendo nada del objeto sino que nos estamos refiriendo a la forma convencional-que hemos aceptado usar cuando tengamos que referimos al objeto.

Supongamos que convenimos en llamar a alguna cosa "roja" y "no-rojas" a todas las demás. La observancia de esta convención, nos impedirá que cuando digamos de un objeto que es rojo, lo designemos simultáneamente como no-rojo. Este razonamiento que nos conducirá al principio de no-contradicción no consiste sino en la estipulación de un modo de aplicar las designaciones de "rojo" y "no-rojo" a los objetos, es decir, una prescripción respecto del método para hablar acerca de los objetos y su validez universal y certeza, su irrefutabilidad; radican en el hecho de no decir nada acerca de los objetos. lógica.

Análogas consideraciones son válidas para el resto de los principios de la

12. Conclusión: existen dos órdenes de enuniciados: 
I) Aquellos que expresan designaciones sobre el comportamiento o las características de un objeto.

2) Aquellos que establecen las relaciones de dependencia entre las designa: ciones atribuibles a los objetos. Éstos se llaman tautologías.

Los primeros pueden ser confirmados o desmentidos mediante una verificación experimental. Los segundos no se refieren a un orden. dentro del área del control verificable y, por ello, son ciertos y necesariamente válidos.

13. Aceptando que los principios lógicos no encierran sino una mera tautología, una deducción lógica no es sino una forma de mostrar relaciones de dependencia respecto de determinadas características o de la exclusión de dichas relaciones. La deducción lógica no agrega conocimiento, sino exhibe el que ya estaba dado implícitamente.

14. La lógica dispone de determinados vocablos denominados "conectivas", con los cuales son posibles las transformaciones tautológicas a través de las distintas manipulaciones de proposiciones, y en el. artículo se dan ejemplos de conectivas y de dichas transformaciones.

15. Si consideramos el orden matemático, precisaremos igualmente que no se refiere a cosas. Las operaciones matemáticas pueden realizarse sin considerar o mencionar ningún objeto material y su referencia propia es la manera como queremos hablar sobre esos objetos. Lo que decimos a través de la expresión de los sumandos y su conexión mediante la operación de sumar, es equivalente a la suma misma, ésta no es sino otro modo de expresión para la misma relación antes mentada. Con ejemplos aclara el articulista este carácter tautológico de la matemálica y la insostenibilidad de las opiniones de Kant y Poincaré respecto a su carácter a-priorístico.

15. Resultan ahora apreciables las diferencias entre la filosofía tradicional y la que se presenta aquí. La concepción típica y dominante ha sido la platónica, según la que, el mundo fue hecho dentro de estos carriles lógico-matemáticos. Nuestro pensamiento modesto, reflejo de la omnisciencia divina, nos fue entregado precisamente para conocer las leyes del mundo.

De los anteriores análisis se infiere, que todas estas relaciones de carácter lógico o matemático, no se refieren a la experiencia ni contienen aisladamente información respecto de ella, sino que se refieren al modo como hablamos, como nos referimos al mundo y que estas diversas formas de expresión, resultan meras transformaciones tautológicas.

17. Una consecuencia importante de esta suerte de consideraciones, reside en la imposibilidad de hacer surgir, mediante el pensamiento y atrás del mundo sensible, un mundo que fuera "el del verdadero ser". El pensamiento no tiene elementos que lo capaciten a decidir de la posible existencia de tales entes, a menos que sea distorsionado y usado incorrectamente, en cuyo caso sí puede esperarse toda suerte de sinsentidos y pseudo-entidades. Pero es conveniente expurgar al conocimiento de este género de errores.

La selección termina con un Indice y una Bibliografía del Positivismo Lógico, Esta última, dividida en tres secciones: 1) Antologia y compilaciones, 2) Libros y 3) Artículos, constituye la bibliografia con mayor acopio de datos y la mejor lograda de todas las que se hayan publicado sobre este tema hasta la fecha, y da muestra de un trabajo paciente y encomiable. ${ }^{22}$

22 Hemas estado a la espera, y eso hace ya un buen tiempo, de aquella ofrecida por H. Feigl y W. Sellars como núm. 10 del vol. Il de la International Encyclopædia of Unified Science. 
Toda selección, como apuntamos líneas antes, descansa parcialmente en el criterio subjetivo de quien la realiza y no considero fácil escapar a las preferencias o simpatías que, conscientemente o no, se deslizan. A sabiendas de que en este caso la autoridad del compilador nos preserva de ello, no sería honesto de mi parte terminar esta crónica sin externarle una inquietud que nació con la meditación sobre su libro. ¿Por qué - pese a cualquier limitación editorial- no se incluyó muestra de la labor de Philipp Frank, Hans Reichenbach o Herbert Feigl, trabajadores desde las épocas de Viena y que tan venturosas exploraciones han hecho dentro de la filosofía de la ciencia física los primeros y de la ciencia natural en general, el último?

C. N. MoLina

Del Centro de Estudios Lógicos 